\title{
On Rings Whose Principal Ideals are Generalized Pure Ideals
}

\section{Husam Q. Mohammad}

husam_alsabawi@yahoo.com

College of Computer Sciences and Mathematics

University of Mosul, Iraq

\section{Received on: 23/04/2006}

\section{ABSTRACT}

Accepted on: 16/08/2006

This paper, introduces the notion of a right PIGP-ring (a ring in which every principal ideal of $\mathrm{R}$ is a GP-ideal ) with some of their basic properties ; we also give necessary and sufficient conditions for PIGP-rings to be a division ring and a regular ring .

Keywords: Generalized pure ideal, principal ideal, Divisor rings, Regular Rings.

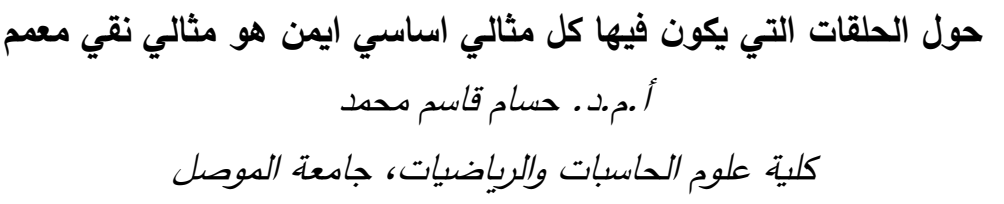

تاريخخ القبول: 2006/08/16

تاريخ الاستلام: 2006/04/23

الملخص

يقدم هذا البحث مفهوم الحلقات من النوع PIGP (الحلقات التي يكون فيها كل جزء مثالي أساسي ايمن هو من النمط GP) وإعطاء الخواص الأساسية لها. كذلك إعطاء الشروط الضرورية والكافية للحلقة PIGP لكي تكون حلقة مقسومة وحلقة منتظمة. الكلمات المفتاحية: المثاليات النقية المعممة, المثالي الاساسي, الحلقات المقسومة, الحلقات

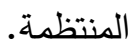

\section{1- INTRODUCTION}

Throughout this paper $\mathrm{R}$ denotes an associative ring with identity . Recall that: (1) A right ideal I of a ring $\mathrm{R}$ is said to be right (left) pure ideal if for every $a \in I$, there exists $b \in I$ such that $a=a b(a=b a)$ [4]. (2) A ring $R$ is said to be a right PIP-ring, if every principal right ideal is pure [1] . (3) A ring $\mathrm{R}$ is called semi-prime ring if $\mathrm{R}$ has no non-zero nilpotent ideal. (4) $\mathrm{A}$ ring $\mathrm{R}$ is called regular ring if for every $\mathrm{a}$ in $\mathrm{R}$, there exists $\mathrm{b}$ in $\mathrm{R}$ such that

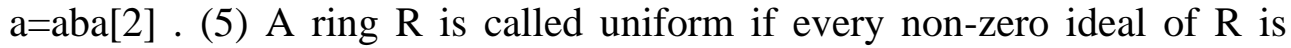
essential .(6) For any $a \in R, r(a),(1(a))$ will denote the right (left) annihilator 
of a . (7) $\mathrm{Y}(\mathrm{R}), \mathrm{Z}(\mathrm{R})$, Cent(R), N stand, respectively, for the right singular ideal, left singular ideal, center of $\mathrm{R}$ and nil radical of $\mathrm{R}$.

\section{2-PIGP-RING}

Following [4], an ideal I is said to be a right(left) generalized pure ideal (briefly GP-ideal) if for every $a \in I$, there exists $b \in I$ and a positive integer $n$ such that $a^{n}=a^{n} b\left(a^{n}=b a^{n}\right)$.

\section{Definition 2.1:}

A ring $\mathrm{R}$ is said to be a right PIGP-ring, if every principal right ideal of $\mathrm{R}$ is a GP-ideal .

\section{Example:}

The ring $\mathrm{Z}_{12}$ of integers modulo 12 is a PIGP-ring .

\section{Lemma 2.2:}

Let $\mathrm{R}$ be PIGP-ring. Then $\mathrm{Z}(\mathrm{R})$ is nilideal .

Proof: Let $z \in Z(R)$, then there exists a positive integer $n$ and $w \in z R$ such that $\mathrm{z}^{\mathrm{n}}=\mathrm{z}^{\mathrm{n}} \mathrm{w}$ where $\mathrm{w}=\mathrm{zr}$ for some $\mathrm{r} \in \mathrm{R}$. Therefore $\mathrm{z}^{\mathrm{n}}=\mathrm{z}^{\mathrm{n}} \mathrm{zr}$. We claim $\mathrm{Rz}^{\mathrm{n}} \cap \mathrm{l}(\mathrm{zr})=0$. Let $\mathrm{x} \in \mathrm{Rz} \cap \mathrm{n}(\mathrm{zr})$, then $\mathrm{x}=\mathrm{yz} \mathrm{z}^{\mathrm{n}}$ and $\mathrm{xzr}=0$ implies that $\mathrm{yz}^{\mathrm{n}} \mathrm{zr}=0$ and we get $x=y z^{n}=0$. So $R z^{n} \cap l(z r)=0$. Since $z \in Z(R)$, then $1(z r)$ is an essential left ideal . Therefore $R z^{n}=0$ and we get $z^{n}=0$, therefore $Z(R)$ is nilideal .

\section{Proposition 2.3:}

Let $\mathrm{R}$ be PIGP-ring with non-zero divisor. Then $\mathrm{R}$ is a division ring .

Proof: Let a be a non-zero element in R. Since R is PIGP-ring, then aR is GP-ideal and hence there exists $b \in a R$ and a positive integer $n$ such that $a^{n}=a^{n} b$, where $b=a r$ for some $r \in R$. Therefore $a^{n}=a^{n}$ ar, whence $(1-a r) \in r\left(a^{n}\right)$. Now since $r(a)=0$, then we get $r\left(a^{n}\right)=0$, which implies that ar $=1$, and hence $\mathrm{a}$ is right invertible. Therefore $\mathrm{R}$ is a division ring .

\section{Theorem 2.4:}

Let $\mathrm{R}$ be a PIGP-ring. Then if $\mathrm{vu}=1$ then $u v=1$ for all $\mathrm{u}, \mathrm{v} \in \mathrm{R}$.

Proof: Let $\mathrm{u}, \mathrm{v} \in \mathrm{R}$ such that $\mathrm{vu}=1$, and since $\mathrm{R}$ is PIGP-ring, then $\mathrm{uR}$ is GPideal and there exists a positive integer $n$ and $r \in R$ such that $u^{n}=u^{n} u r$.

Since $v u=1$ then $v^{n} u^{n}=v^{n+1} u^{n+1}=1$ and we get $u^{n+1}=u^{n+1} v^{n+1} u^{n+1}$ and $u^{n+1} r=u^{n+1} v^{n+1} u^{n+1} r$ so $u^{n}=u^{n+1} v^{n+1} u^{n}$ and implies that $u^{n}=u^{n+1} v\left(v^{n} u^{n}\right)=u^{n+1} v$ Now $u v=v^{n} u^{n}(u v)=v^{n}\left(u^{n+1} v\right)=v^{n} u^{n}=1$ 
Clearly every PIP-rings is PIGP-ring, however the converse is not true. We now consider a necessary and sufficient condition for PIGP-ring to be PIP-ring.

\section{Theorem 2.5:}

Let $\mathrm{R}$ be a PIGP-ring and $\mathrm{r}\left(\mathrm{a}^{\mathrm{n}}\right) \subseteq \mathrm{r}(\mathrm{a})$ for every $\mathrm{a} \in \mathrm{R}$ and a positive integer $\mathrm{n}$. Then $\mathrm{R}$ is a PIP-ring.

Proof: Assume that R is a PIGP-ring . Then for any principal ideal I is GPideal , and for any $\mathrm{x} \in \mathrm{I}$ there exists a positive integer $\mathrm{n}$ such that $\mathrm{x}^{\mathrm{n}}=\mathrm{x}^{\mathrm{n}} \mathrm{y}$, for some $y \in I$, so $x^{n}(1-y)=0$ implies that $(1-y) \in r\left(x^{n}\right)$ and since $r\left(x^{n}\right) \subseteq r(x)$ so $\mathrm{x}=\mathrm{xy}$.Therefore $\mathrm{I}$ is pure consequently $\mathrm{R}$ is PIP-ring .

Recall that a ring $R$ is called that zero-commutative [3] if $a b=0$ implies that $b a=0$ for all $a, b \in R$.

\section{Theorem 2.6:}

Let $\mathrm{R}$ be a zero-commutative PIGP-ring. Then there exists an invertible $\mathrm{u} \in \mathrm{R}$ and idempotent element $\mathrm{e} \in \mathrm{R}$, such that $\mathrm{a}^{\mathrm{n}}=\mathrm{eu}=\mathrm{ue}$ and $a^{n}=(1-e)+u$ for some positive integer $n$ and $a^{n} u=u$ a $a^{n}$

Proof: Let $0 \neq a \in R$ and since $R$ is a PIGP-ring, then aR is GP-ideal, so there exists a positive integer $n$ and $r \in R$ such that $a^{n}=a^{n} a r$, and since $R$ is zerocommutative then $\left(a^{n-1}-a^{n} r\right) \in r(a)=l(a)$ implies that $a^{n}=a^{n}$ ra and $a^{n}=a^{n}$ arra and so we get $a^{n} r^{n} a^{n}=a^{n} b a^{n}$, where $r^{n}=b$.

Now, let $e=a^{n} b$ and $e^{2}=a^{n} b a^{n} b=a^{n} b=e$. So e is idempotent and $a^{n} e=e a^{n}=a^{n}$. Let $\mathrm{u}=1-\mathrm{e}+\mathrm{a}^{\mathrm{n}}$ and $\mathrm{v}=1-\mathrm{e}+\mathrm{eb}$ $u v=\left(1-e+a^{n}\right)(1-e+e b)=1-e+e b-e^{2} b+a^{n} e b=1-e+e a^{n} b=e+e^{2}=1$ and applying theorem 2.4 we have $v u=1$. Now eu=e(1-e+ $\left.a^{n}\right)=e a^{n}=a^{n}$. Therefore $\mathrm{a}^{\mathrm{n}}=\mathrm{eu}=\mathrm{ue}$ and $(1-\mathrm{e})+\mathrm{u}=1-\mathrm{e}+\mathrm{a}^{\mathrm{n}}+\mathrm{e}-1=\mathrm{a}^{\mathrm{n}}$. Thus $\mathrm{a}^{\mathrm{n}}=(1-\mathrm{e})+\mathrm{u}$.

The following theorem gives a condition for PIGP-ring be a regular ring.

\section{Theorem 2.7:} ring .

Let $\mathrm{R}$ be a PIGP-ring and $\mathrm{r}\left(\mathrm{a}^{\mathrm{n}}\right) \subseteq \mathrm{r}(\mathrm{a})$ for all $\mathrm{a} \in \mathrm{R}$. Then $\mathrm{R}$ is a regular

Proof: For any $a \in R$, we have to prove that $a R+r(a)=R$, if not , then there exists a maximal right ideal $M$ such that $a R+r(a) \subseteq M$.Since $R$ is a PIGPring, then $\mathrm{aR}$ is GP-ideal and there exists a positive integer $n$ and $r \in R$ such that $a^{n}=a^{n}$ ar . We get $(1-a r) \in r\left(a^{n}\right)$. Since $r\left(a^{n}\right) \subseteq r(a)$ then $(1-a r) \in r(a) \subseteq M$ 
implies that $1 \in M$ which is a contradiction . So $a R+r(a)=R$, and $a=a b a$ for some $b \in R$. Then $R$ is a regular ring .

Corollary 2.8:

Let $\mathrm{R}$ be a PIGP-ring, then any reduced ideal is regular .

\section{Lemma 2.9:}

If $\mathrm{R}$ is a semi-prime ring then $\mathrm{r}\left(\mathrm{a}^{\mathrm{n}}\right)=r(\mathrm{a})$ for any $\mathrm{a} \in \operatorname{Cent}(\mathrm{R})$.

Proof: See [5] .

\section{Corollary 2.10:}

Let $\mathrm{R}$ be a semi-prime PIGP-ring . Then $\operatorname{Cent}(\mathrm{R})$ is a regular ring .

\section{Lemma 2.11:}

Let $\mathrm{R}$ be a zero-commutative ring, then $\mathrm{N} \subseteq \mathrm{Y}(\mathrm{R})$.

Proof: See [6] .

Our next result characterizes a uniform PIGP-ring in terms of nilpotent and non-zero divisor

\section{Theorem 2.12:}

Let $\mathrm{R}$ a be zero-commutative uniform ring . Then $\mathrm{R}$ is a PIGP-ring if and only if :

1- For every element of $\mathrm{R}$ is either non-zero divisor or nilpotent

2- Every non-zero divisor of $\mathrm{R}$ is an invertible

3- $\mathrm{N}$ is a right ideal in $\mathrm{R}$.

Proof: Let $\mathrm{R}$ be a zero-commutative uniform PIGP-ring .Let a be a nonzero element in $\mathrm{R}$. Then $\mathrm{aR}$ is a GP-ideal and hence there exists a positive integer $n$ and $r \in R$ such that $a^{n}=a^{n} a r$. We claim that $a^{n} R \cap r(a)=0$, let $\mathrm{x} \in \mathrm{a}^{\mathrm{n}} \mathrm{R} \cap \mathrm{r}(\mathrm{a})$. Then $\mathrm{x}=\mathrm{a}^{\mathrm{n}} \mathrm{s}$ and $\mathrm{ax}=0$ for some $\mathrm{s} \in \mathrm{R}$ and $\mathrm{ax}=\mathrm{a}\left(\mathrm{a}^{\mathrm{n}} \mathrm{s}\right)=0$ implies that $\mathrm{sa}^{\mathrm{n}+1}=0$ [since $\mathrm{R}$ is a zero-commutative ] and we get $\mathrm{sa}^{\mathrm{n}+1} \mathrm{r}=0$ implies that $\mathrm{sa}^{\mathrm{n}}=0$ and $\mathrm{x}=\mathrm{a}^{\mathrm{n}} \mathrm{s}=0$. So $a^{\mathrm{n}} \mathrm{R} \cap \mathrm{r}(\mathrm{a})=0$. Since $\mathrm{R}$ is a uniform ring, then either $r(a)$ is essential then $a^{n} R=0$. This implies that $a^{n}=0$, so $a$ is nilpotent , or $a^{n} R$ is essential then $r(a)=0$. This implies that a is a non-zero divisor and applying proposition 2.3 then any non-zero divisor is invertible and applying lemma 2.2 and 2.11 , then $\mathrm{N}=\mathrm{Y}(\mathrm{R})$, so $\mathrm{N}$ is a right ideal in $\mathrm{R}$.

Conversely: For any $\mathrm{a} \in \mathrm{R}$. If a is a non-zero divisor then a is invertible and $\mathrm{aR}=\mathrm{R}$ which is a GP-ideal . On the other hand, if a is nilpotent then $\mathrm{a}^{\mathrm{m}}=0$ for some positive integer $\mathrm{m}$ and since $\mathrm{N}$ is a right ideal then $\mathrm{aR}$ is a GP-ideal. 


\section{Theorem 2.13:}

Let $\mathrm{R}$ be a commutative PIGP-ring .Then $\operatorname{Rad}(\mathrm{aR})=\mathrm{aR}+\mathrm{N}$. for all $a \in R$

Proof: Since $\mathrm{aR} \subseteq \operatorname{Rad}(\mathrm{aR})$ and $\mathrm{N} \subseteq \operatorname{Rad}(\mathrm{aR})$, then $\mathrm{aR}+\mathrm{N} \subseteq \operatorname{Rad}(\mathrm{aR})$. Now let $\mathrm{x} \in \operatorname{Rad}(\mathrm{aR})$, then there exists a positive integer $\mathrm{m}$ such that $\mathrm{x}^{\mathrm{m}} \in \mathrm{aR}$ and since $R$ is a PIGP-ring, then there exists a positive integer $n$ and $b \in a R$ such that $x^{m n}=x^{m n} b$ and we get $x^{m n}(1-b)=0$.

Then $[\mathrm{x}(1-b)]^{\mathrm{mn}}=\mathrm{x}^{\mathrm{mn}}(1-b)^{\mathrm{mn}}=0$,

so $x(1-b) \in N$, and because $b x \in a R$, we have

$x=b x+x(1-b) \in a R+N$. Thus $\operatorname{Rad}(a R)=a R+N$. 


\section{REFERENCES}

[1] Ahmad, Sh. H. (2006) "On Rings Whose Principal ideal are Pure", RAf. Jour. Of Comp. \& Math's.Vol.3,No.2,PP.53-57

[2] Goodearl, K.R. (1979) Von Neumann regular rings , London, Pitman.

[3] Kim, N.K.; S.B. Nam, and J.Y. Kim (1999) "On Simple Singular GP-Injective Modules", Communications in Algebra, Vol.27,No.5, PP.215-218 .

[4] Mahmod, R. D. (2000) "ON Pure Ideals and Pure Sub-Modules", Ph.D. , Thesis, Mosul University .

[5] Nam, S.B. (1999) "A note on Simple Singular GP-Injective Modules”,Kangweon-Kyungki Math. Jour., Vol.7,No.2,PP.215-218.

[6] Shuker, N.H. and A.S. Younis (2005) " A note on non-Singular ring” RAf. Jour. of Comp. and Math's, Vol. 2, No. 2 , PP.21-26. 